\title{
Understanding Teachers' Integration of Moodle in EFL Classrooms: A Case Study
}

\author{
Yasir Al Yafaei ${ }^{1} \&$ Rais Attamimi ${ }^{1}$ \\ ${ }^{1}$ English Language Centre, Salalah College of Technology, Salalah, Oman \\ Correspondence: Yasir Al Yafaei, School of Education, Exeter, 73 Roberts Road, EX2 4HE, United Kingdom.
}

Received: January 24, 2019 Accepted: February 27, 2019 Online Published: March 1, 2019

doi: $10.5539 /$ elt.v12n4p1 URL: https://doi.org/10.5539/elt.v12n4p1

\begin{abstract}
The study explores the integration and implementation of the Moodle platform at the English Language Center of the Salalah College of Technology. To achieve this purpose, a qualitative, interpretive approach with a case study research design was used to collect the data and to deepen our understanding of the phenomena and how it was constructed in social reality of the school.Two teachers have been chosen to be the interviewees, to give their opinions and views on the topic under study, and the factors affecting both the implementation and integration of the Moodle programme. It was evident from the narratives of the two interviewees that the integration of Moodle was successful, and that it has proven to be a useful tool in the teaching and learning processes of English. In spite of some existing factors that may hinder the working mechanisms of the implementation and integration of Moodle, it may be concluded that this platform could be recommended to be extended to the other skills of the English language that it currently does not support. Following this process will inevitably improve the comprehension and production of the English language and related materials, online and real, respectively.
\end{abstract}

Keywords: English language, teaching, learning, moodle platform, EFL learners

\section{Introduction}

\subsection{Theoretical Background}

Nowadays, technology has been transformed into becoming fundamental part of our daily lives as well as specifically in the field of education everywhere throughout the entire globe. Every several years, a high number of educational institutions are spending increasing amounts of money to reform their systems for the purpose of bridging the existing technological gaps in the curriculum (Buabeng-Andoh, 2012). This process of reform requires an effective implementation of technology in the affected curriculums to help teachers make a successful integration of different kinds of technologies (Tomei, 2005).

In line with these rapid technological developments, the Salalah College of Technology (SCT) in Dhofar Governate of the Sultanate of Oman, has executed an ambitious programme to provide its students and teachers in the English Language Center with all of the needed facilities required for enhancing the instruction and acquisition of English (Alyafaei \& Attamimi, 2018). The college has introduced online open-source learning software in teaching English, which has been universally referred to as the acronym of "Moodle". Moodle stands for "Modular Object-Oriented Dynamic Learning Environment". According to Brandle (2005), Moodle is designed to encourage teachers to create quality online instruction. Likewise, it is simultaneously used to grant students the freedom on deciding which activities they prefer to participate in and in what form, and to what degree, the participation will take place (Littlejohn \& Pegler, 2007). Additionally, Moodle could be used to develop the learners' language skills, as well as to encourage students to interact online with their teachers and their classmates as well (Al-Ani, 2008).

Since the spring of the academic year 2014-2015, courses offered within the English Language Centre have been systematically generated within the Moodle e-learning platform in an exact parallel direction with the face-to-face teaching method. This approach has aimed at providing Omani students with additional support for the four English language skills, namely, reading, writing, speaking and listening. The courses have been provided as a blended learning venue, where the classroom activities are supported by Moodle. The assignments, tests and other learning activities in Moodle are strongly interrelated with the lessons which are taught in the 
classrooms in a way that encourages students to gain a much deeper, more comprehensive understanding of their language courses.

\subsection{Factors Influencing Teacher's Integration of Moodle}

A bulk of studies have been undertaken to explore the factors that could affect the incorporation of the Moodle platform in many EFL contexts. Many studies in this field have previously revealed an inherent interest on the part of both teachers and students to incorporate Moodle in language education, as they believe that the use of it enhances the language learning process (Banerjee, 2011; Henderson, 2010; Alani, 2013). Additionally, the implementation of Moodle encourages a student-centered approach in which both teachers and students take part in the classroom, and the focus of instruction is shifted from the teachers to the students. There has been a range of research showing that Moodle usage enriches overall learning inside and outside the classroom (Alani, 2008; Govender, 2009; Georgouli, Skalkidis, \& Guerreiro, 2008). In this respect, Moodle carries an importance in the universities as an essential part of the blended learning option which is generally described as a combination of face-to-face and online approaches to instruction.

Besides the advantages of Moodle, some challenges should be acknowledged as they are likely to influence the implementation of Moodle in the language classroom. Banerjee (2011), for example, conducted a survey to study students' satisfaction with blended learning. He argued that students' satisfaction depends primarily on the difficulties presented by the topic, how much self-directed learning is needed and the effectiveness of the selected pedagogical methods that are employed in each given case. Similarly, MacKeogh and Fox (2009) qualitatively investigated the factors that may affect the motivation of the individual students to engage in blended learning. The results demonstrated that many teachers continue to prefer face-to-face lectures as they are doubtful about the potential for student learning online. The study illustrated other barriers such as lack of time, lack of technical support and fear of the loss of control over the classroom. Perez and Medallon (2015) addressed some obstacles like poor Internet connections and lack of knowledge of Moodle use on the part of the teachers. It can be seen that there are some intrinsic and extrinsic barriers which might affect the successful integration of Moodle, so teachers are required to tackle them and find solutions to overcome any obstacles.

Concerning the context of the current study, two important studies by Al Busaidi and Tuzlukova (2013) and Alani (2013) have been carried out to explore the effectiveness of Moodle on students' learning at Sultan Qaboos University. The results indicated that the Moodle platform has tremendously enhanced language learning practices among students at the university due to the flexibility and facility of access. However, both studies made no attempt to offer adequate information or explanation on how EFL Omani teachers integrated Moodle in their teachings.

\subsection{Rationale of the Study}

Omani EFL teachers are highly encouraged by SCT to make use of the facilities available in the computer laboratories as an integral component of their teachings. Thus, some English language classes are taught in the computer laboratories in order to encourage students to make use of the Moodle platform. However, no study has been carried out in Oman to study the way in which teachers are integrating Moodle in EFL classrooms. My experience as a lecturer at the college suggests that many teachers might react negatively towards implementing a new teaching technique, especially when it comes to technology. They might argue that Moodle seems to be an extra burden on them imposed by the college for which they have no input on to what degree, or even whether or not, to deal with it. According to Cosh (1999), "unless they are accepted by the staff, the only relevance of those schemes is likely to be to accountability, rather than genuine teacher development" (p. 23). To explore the extent to which this might be the case, this study investigates the way in which Omani EFL teachers incorporate Moodle in their teachings at the English Language Centre of SCT.

\subsection{Main Research Questions}

The purpose of the study is to qualitatively investigate how Omani EFL teachers integrate or implement Moodle in the teaching of the English language at the English Language Centre of SCT. Specifically, this research addresses the following questions:

1) How do Omani EFL teachers integrate Moodle in their classrooms?

2) What are the factors that influence their integration of Moodle in their teachings?

\section{Method}

The current study is interpretivist in its nature, as it aims to gain a deeper understanding of the use of the Moodle platform in Omani EFL classrooms, and not to generalize the results to the whole population. In order to 
optimally achieve these stated aims, a case study research design was employed to collect the data required to answer the research questions.The choice of this design was based on a set of reasons. First, the study was exploratory in nature as it sought to explore the phenomenon of the intergration and implementation of Moodle at the English Language Center of SCT where not much data was available about this phenomenon at the time when this study was being conducted. Second, such a case study design was deemed to be appropriate as it would help us gain more in-depth information on the topic under study and would inevitably widen our understanding of the phenomenon.

In recent years, the interview has increasingly emerged as a common data method of data for research studies which seeks out a thorough and rich understanding of a specific issue (Kajornboon, 2005). Since this method happens to satisfy the aim of this study, interviews were chosen to be the method of my investigational inquiry. More precisely, semi-structured interviews were my source of data, by which I could understand the same phenomenon from different perspectives. A semi-structured mode of interviewing design was employed, as it was the most likely research vehicle by which the research questions could be most effectively answered. Both of my research questions were best answered by qualitative research methods that generated qualitative data. Epistemologically, semi-structured interviews were chosen as the meaning is here constructed between the researcher and the participants in the research site

\subsection{The Interviews}

The conducted interviews included two main sections. The first section was designed to understand the way in which the interviewees integrate Moodle into their teaching. For example, aspects of Moodle which are used, what activities are implemented, the role of the teachers and students inside and outside the classroom and so on, were all covered. The second section was developed to elicit the factors that are likely to influence the teacher's implementation and integration of Moodle in their classes.

After the stage of researching, the next step was to prepare the interview questions. An important point to note is that the questions were formed in a way that led to open-ended answers. Asking a closed-end question may not help the interviewer gain an in-depth understanding of the topic. For the case of the current study, open-ended questions were the perfect instrument for my perceived data-collecting purposes. These were the key components that were considered during the preparation of the interview.

A pilot version of the interview questions was sent to an academic colleague who is currently implementing a Moodle platform. He was consulted about the study and the questions of the interviews through email communications. He suggested deleting questions no. 7 and 11 as they were parts of other questions which had already been included. Furthermore, he recommended making some modifications in the phrasing of questions no. 3, 5, 8 and 10 to avoid close-ended and neutral answers.

\subsection{Participants and Sampling}

The target population of this research included only the EFL teachers' academic year 2017-2018. Due to time limitations, a non-random convenience sampling was employed to include whoever was available at the time of conducting the research. Two EFL Omani teachers have been selected to be the interviewees. Both of them are currently teaching at the college, and they are implementing Moodle in their teachings. They have rich experience in this field since they have been using Moodle for more than five years. Therefore, they were ideal candidates/subject to seek more of their views regarding the implementation of Moodle through the interviews.

\subsection{Data Collection Procedure}

Prior to conducting this study, an e-mail with a copy of the interview questions was sent to the administration of SCT to gain their permission to conduct the interviews with two lecturers at the college. After that, the head of the English Language Centre sent another e-mail to the lecturers who are implementing Moodle in their classes requesting them to collaborate in the process.

It was endeavored to conduct as many face-to-face interviews as possible as they have been widely used as an interview technique in the field of qualitative research. However, this was not possible due to temporal and financial constraints. Also, doing direct research on teachers in the physical location where direct face-to-face communication was not feasible, paved the way towards carrying out the interviews through WhatsApp video-calls and Skypes both interviewees were in favor of the substituted communication channel. As one interviewee mentioned "I prefer to do the interview by telephone even if it takes more than an hour. I think my colleagues will be in favor of it as well". This is reasonable, as telephone interviewing has become more common in the last two decades due to the rapid pace of developments in the applicable technology (Cachia \& Millward, 2011). Any researcher can conduct interviews with people all over the world if they have access to a 
telephone. Thus, it saves time and reduces the cost of the face to face interview, as there is no need to travel to different places for conducting the interviews. Another important characteristic of the telephone interview is that it provides flexibility in setting up the appointment on a time that is most suitable to the interviewees. However, due to the more recent developments in the related technology, the interviewer can see the interviewees through the use of video-calls, to take one example, so social cues are still available as a source of extra information.

\section{Discussion}

The answers to these two given research questions by the two interviewees will be given following two different approaches of reporting results. In the case that both of the answers given were identical, they will be treated as one collective response. Whereas, in the case that the answers given were different or not strictly identical, they will be treated discretely, with the differences themselves explicitly highlighted. For the first type of question, as to how teachers integrate Moodle into their teachings, the responses of the two teachers were identical, as both teachers have reported that, in terms of integration and implementation, the two terms should be dealt with different levels of discretion. As teachers of the English language, who have been requested to use the Moodle platform to teach SCT students subjects such as grammar, or more instrumental subjects such as the class communication projects, the school has already taken the step of integrating this platform into the school curriculum. And, as teachers, according to the effective study plans, we will have the responsibility to implement all of the Moodle aspects into all classrooms. This proposed implementation, as well as the associated schedule and benchmarks of progress to be gleaned from such implementation, has several benefits and drawbacks, according to the best estimate of the two interviewees, there is a decided variation in the amount and degree of Moodle integration that currently exists within the fourth level of the English Language Center, which to this point is the only level required to make explicit use of the Moodle platform. The teachers who teach in the levels before the fourth level of instruction are recommended to make use of Moodle in only a piecemeal fashion, such as to help accommodate the learning of individual aspects of curriculum, namely grammar or reading, but nothing approaching the kind of systemic comprehension deemed to be necessary for inclusion in level four.

Responding to the second research question of the study, the two interviewed teachers have given diverse factors that influence the integration of Moodle inside the classroom, both positively and negatively. The factors could be classified on three different stages or levels: existing infrastructure, the entry level of expertise carried by students who come with different educational outcome expectations and the level of expertise of the teachers who will be assigned to guiding and assessing their classwork that is to be generated by Moodle. One of the more interesting responses given by an interviewee in the interview was that infrastructure and computers are a baseline consideration for any successful implementation of Moodle. In this regard, the conditions that exist for Moodle reception, and computer and Internet coverage of any kind, are at best variable in several of the potential classrooms or dedicated computer laboratories where Moodle would be conceptually integrated. With regard to this one of the interviewees has said:

“...It is very essential for me to make sure that all of the computers are available for the students before commencing the class..."

The other interviewee did not rate the existent of infrastructure to be as important as the first interviewee, but has instead focused on the students' level of expertise in using computers and other software instruments. The second interviewee stated:

“... The students' knowledge of using computers is the main factor to ensure a useful use of the Moodle platform, without their mastery of computer skills, nothing will be done in the Moodle..."

He has further declared that the level of computer knowledge of students in level 4, as well as other levels in which he has taught and used Moodle, is far from optimal. Furthermore, he regarded this condition as an obstacle to the elementary implementation of Moodle, as well as the basic conduction of classes. Regarding this point, the first interviewee has added that students enrolled in IT-dedicated classes at the English Language Center should be given introductory exposure to computers, software and general computer literacy issues that will enable those students to more successfully use and integrate Moodle into their learning experiences. They both agreed that:

“...students have to go through a training process prior to introducing any new approach, especially when it comes to using technology..."

Finally, the two interviewees agreed that the level of teachers' expertise is of paramount importance to the success of Moodle implementation in the classrooms. They have stated that teachers involved in the programme have very diverse and wide-ranging differences in the levels of accommodation and knowledge of computers 
going into the classroom, which will naturally influence and effect their efforts to give Moodle a wider exposure within the curriculum that all are expected to deliver. From these responses, it has been found that younger teachers are better at using computers, whereas older teachers lack some basic skills that allow them to use computers readily and easily. For these reasons, both interviewees recommend further workshops and official exposure to Moodle and other forms of computer aided language learning. Also, both interviewers agree that Moodle can be used as an inspirational tool in motivating students to learn English. Moodle has been proven to be an effective online platform from which students can accomplish all of the assigned tasks. Students enjoy it because it can encourage team work and group work, and in so doing, increases the general level of motivation for all students to continue to learn and study the English language, as well as achieving the intended learning outcomes set by national and regional policymakers and stakeholders in the Sultanate of Oman.

\section{Conclusion}

It can be concluded that Moodle, as a platform, is a useful tool to be used in language learning classes in general, and it is evident within the context of the English Language Center of the Salalah College of Technology. The two teachers involved in the study have expressed their inherent interests regarding the integration of the Moodle platform in their classrooms, and have listed a number of reasons why the integration of Moodle has been the right decision to have been made. Despite the drawbacks that may be connected to some lacking aspects in the infrastructure of the school, as well as the lack of exposure and knowledge of this and other available online platforms by students and staff alike, these areas of concern may still be remedied and improved on. Above all, the Moodle platform, from the testimony of the two teachers in the study, different levels of students may be able to use the Moodle platform, as it enhances and improves the learning experience for students and teachers, and furthermore, it gives the institute at large another delivery system from which to gather information and culture, as well as constructive commentary and feedback from the people who use it.

It is highly recommended that a large scale study on Moodle should be carried out in the future, with a larger and more diverse body of respondents. This study has been based upon the analysis of only two individual teachers, which could be considered to be a limitation, to the degree that the voices of students should also be included, in order to further elaborate upon the use, nature of integration of the Moodle platform within this English as a Foreign Language context, where we will obtain more insightful perspectives and contrastive feedback on the implications and integrations of Moodle into the larger educational framework, as well as factors which could be deemed as detrimental to a successful integration and adaptation of this secure and broad-based learning management system (i.e., Moodle).

\section{References}

Al-Ani, W. (2008). English as foreign language student teachers' perception of the use of Moodle in foundations of education course. Malaysian Journal of Learning and Instruction, 5, 63-78.

Al-Ani, W. (2013). Blended learning approach using Moodle and student's achievement at Sultan Qaboos University in Oman. Journal of Education and Learning, 2(3), 96-110. https://doi.org/10.5539/jel.v2n3p96

Al-Busaidi, S., \& Tuzlukova, V. (2013). Some reflections on Moodle-based learning in the English Foundation Programme of Sultan Qaboos University. Asian Journal of Social Sciences \& Humanities, 2(3), 166-173.

Alyafaei, Y., \& Attamimi, R. (2018). Teachers' knowledge of and attitude towards incorporating Computer Assisted Language Learning in EFL classrooms. International Journal of Linguistics, Literature and Culture (LLC), 5(4), 57-76. https://doi.org/10.19044/llc.v5no4a5

Banerjee, G. (2011). Blended environments: Learning effectiveness and student satisfaction at a small college in transition. Journal of Asynchronous Learning Networks, 15(1), 8-19. https://doi.org/10.24059/olj.v15i1.190

Brandle, K. (2005). Are you ready to Moodle? Language Learning Technology, 9(2), 16-23.

Buabeng-Andoh, C. (2012). Factors influencing teachers' adoption and integration of information and communication technology into teaching: A review of the literature. International Journal of Education and Development using Information and Communication Technology, 8(1), 136.

Cachia, M., \& Millward, L. (2011). The telephone medium and semi-structured interviews: A complementary fit. Qualitative Research in Organizations and Management: An International Journal, 6(3), 265-277. https://doi.org/10.1108/17465641111188420

Cosh, J. (1999). Peer observation: A reflective model. ELT Journal, 53(1), 22-2. https://doi.org/10.1093/elt/ 53.1 .22

Georgouli, K., Skalkidis, I., \& Guerreiro, P. (2008). A framework for adopting LMS to introduce e-learning in a 
traditional course. Educational Technology \& Society, 11(2), 227-240.

Govender, L. (2009). Teachers' Participation in Policy Making: The Case of the South African Schools Act. (PhD dissertations, University of the Witwatersrand).

Henderson, J. G. (2010). Learning through a disciplined curriculum study approach: Implications for educational leadership. Scholar-Practitioner Quarterly, 4(4), 312-315.

Kajornboon, A. B. (2005). Using interviews as research instruments. E-journal for Research Teachers, 2(1), 1-9.

Littlejohn, A., \& Pegler, C. (2007). Preparing for blended e-learning. Routledge. https://doi.org/10.4324/ 9780203961322

Mackenzie, N., \& Knipe, S. (2006). Research dilemmas: Paradigms, methods and methodology. Issues in Educational Research, 16(2), 193-205.

MacKeogh, K., \& Fox, S. (2009). Strategies for embedding e-learning in traditional universities: Drivers and barriers. Electronic Journal of e-Learning, 7(2), 147-154.

Perez, M. D., \& Medallon, M. (2015). A move to Moodle: A perspective of academics in the College of International Tourism and Hospitality Management. Laguna Journal of Multidisciplinary Research, 4(3), 49-71.

Schwandt, T. A. (2007). The Sage Dictionary of Qualitative Inquiry. London: Sage Publications. https://doi. org $/ 10.4135 / 9781412986281$

Tomei, L. A. (2005). Taxonomy for the technology domain. USA: Information Science Publishing. https://doi. org/10.4018/978-1-59140-524-5

\section{Copyrights}

Copyright for this article is retained by the author(s), with first publication rights granted to the journal.

This is an open-access article distributed under the terms and conditions of the Creative Commons Attribution license (http://creativecommons.org/licenses/by/4.0/). 